\title{
Sol-gel-processed silica/polydimethylsiloxane/calcium xerogels as polymeric matrices for Metronidazole delivery system
}

\author{
Katarzyna Czarnobaj
}

Received: 4 February 2010/Revised: 10 June 2010/Accepted: 22 June 2010/

Published online: 1 July 2010

(C) The Author(s) 2010. This article is published with open access at Springerlink.com

\begin{abstract}
Silica, silica/polydimethylsiloxane and silica/polydimethylsiloxane/ calcium xerogels were examined as polymeric carriers for the controlled release of drug-Metronidazole. Characterization assays comprised analysis of the matrix by Fourier transform infrared spectroscopy (FTIR), determining the specific surface area of solids (BET) and scanning electron microscope (SEM) techniques and further monitoring in the ultraviolet and visible light regions (UV-Vis) of the in vitro release of the drug over time. Using tetramethoxysilane (TMOS) as a precursor of silica matrix and polydimethylsiloxane (PDMS) and calcium ions as additives, xerogels with different morphology and physical properties were obtained. The applied modifications diminished the porosity and hydrophilicity of the silica matrix as well as reduced the release of drug. Based on the presented results of this study, it may be stated that applied xerogel matrices, pure silica $\left(\mathrm{SiO}_{2}\right)$ and modified silica $\left(\mathrm{SiO}_{2}-\mathrm{CaO}, \mathrm{SiO}_{2}-\mathrm{PDMS}\right.$ and $\left.\mathrm{SiO}_{2}-\mathrm{CaO}-\mathrm{PDMS}\right)$, could be promising candidates for the formulation in local delivery systems.
\end{abstract}

Keywords Sol-gel method $\cdot$ Silica xerogels $\cdot$ Drug delivery $\cdot$ Controlled release

\section{Introduction}

The use of the sol-gel-processed silica materials as biocatalysts, biosensors, immunodiagnostics or drug delivery systems, in both medicine and the pharmaceutical industry, is well reported in the literature [1-10].

The sol-gel procedure is highly efficient due to the low temperature of the chemical process, high homogeneity and product purity, which enables the insertion

K. Czarnobaj (ه)

Department of Physical Chemistry, Medical University of Gdańsk, al. Gen. J. Hallera 107, 80-416 Gdańsk, Poland

e-mail:kczar@gumed.edu.pl 
of numerous biologically active substances into the preparation. Entrapped molecules retain their conformation, physical characteristics and many of their chemical and biological properties within the sol-gel materials. Owing to the porosity of the sol-gel matrix, the molecules are accessible to the external liquid through the pore network and may be released in a controlled manner from the matrix to the surrounding liquid. Amorphous biomaterials obtained in this way are characterized by in vivo biocompatibility and bioactivity since the sol-gel networks can provide heterogeneous nucleation sites for growth of biological apatite layers [11-14].

Generally, the sol-gel method involves the hydrolysis of a metal oxide or alkoxide precursor solution to form a colloidal dispersion-sol, which then undergoes crosslinking to form a three-dimensional solid network-gel, and further, after drying-xerogel [15-17].

The sol-gel technique can be used to synthesize pure $\mathrm{SiO}_{2}$, organically modified silicates by partially replacing TMOS with organic molecules or polymers (PDMS, PEG and PCL) or inorganically modified with: $\mathrm{CaO}, \mathrm{P}_{2} \mathrm{O}_{5}, \mathrm{TiO}_{2}, \mathrm{ZrO}_{2}$.

Structures of these polymer gels can be obtained by chemical or physical processes. Some gels are cross-linked chemically by covalent bonds (chemical gel), whereas other gels are cross-linked physically by weak forces, such as hydrogen bonds, van der Waals forces, or hydrophobic and ionic interactions (physical gel). Pure silica consists of chemical, covalent bonds between silicon and oxygen atoms. Organically modified silica (e.g. PDMS) can include both chemical bonding and physical interaction (van der Waals or hydrophobic forces). Inorganic oxides (e.g. $\mathrm{CaO}$ ) often form ionic bonds with silica creating a bond between oxygen atoms and cations used [18].

These modifications influence the structure and properties of the obtained matrices, change the hardness, density, porosity and, in consequence, change the release of biologically active substances (e.g. drugs) [19-21].

Drug molecules are incorporated into the sol-gel matrices by superficial adsorption (or covalent bonding) or by trapping the molecules in the forming gel [22].

The latter method is particularly interesting, as not many other matrices offer such possibilities. Doping some admixture to a colloidal liquid and gelating it result in the occludation of a molecule in the formed bonds of oxide network. A consequence of such initiated immobilisation mechanism is the fact that molecules of variable shapes, sizes and electric charges may be trapped.

In this study, Metronidazole was chosen as the model drug for preparing controlled delivery systems. Metronidazole is a drug with activity against anaerobic protozoa, aerobic and microaerophilic bacteria [23, 24]. In medicine, it is used in the treatment of severe bacteria infections, protozoa genital infections, and as a prophylactic agent before abdominal surgery. The antibacterial activity against anaerobic cocci, gram-negative and gram-positive bacilli has led to its use in the treatment of periodontal disease. Its formula is 2-methyl-5-nitroimidazole-1-ethanol with an empirical formula of $\mathrm{C}_{6} \mathrm{H}_{9} \mathrm{~N}_{3} \mathrm{O}_{3}$ and molecular weight 171.16. The molecular structure is presented in Fig. 1. 
Fig. 1 The molecular structure of Metronidazole

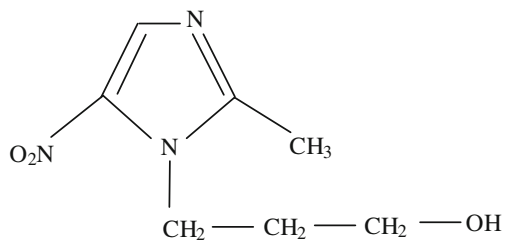

Oral administration of Metronidazole induces some side effects like hypersensitivity, gastrointestinal intolerance and development of bacterial resistance $[25,26]$. Moreover, such a form of application does not give a suitable concentration at the action site. This efficacy may be improved by the use of local drug delivery systems. Alternate dosage forms, in which Metronidazole is sustain released from a drug carrier, could bring about improved therapeutic activity, reduction dosing frequency and systemic toxicity. The polymers, poly( $\varepsilon$-caprolactone), polyethyleneglycol, hydroxyethyl cellulose, polysiloxanes, natural zeolites and silica and titanium oxides, calcium phosphate, hydroxyapatite, can be applied as solid dosage forms in controlling the release of drug and implanted in the vicinity of infection site $[23,25$, 27-29]. In this study, as carrier systems for Metronidazole used the $\mathrm{SiO}_{2}, \mathrm{SiO}_{2}-\mathrm{CaO}$, $\mathrm{SiO}_{2}-\mathrm{PDMS}$ and $\mathrm{SiO}_{2}-\mathrm{CaO}-\mathrm{PDMS}$ xerogels. These samples may be used as bonesubstitute materials especially in surgical orthopedics and dentistry by reason of the bioactive inorganic species-silanol groups $(\mathrm{Si}-\mathrm{OH})$ of hydrolyzed TMOS and calcium ions as well as good flexibility - as result of addition of PDMS.

The drug was incorporated into the xerogels on the stage of the sol. Subsequently, the research was aimed to determine the kinetics of Metronidazole release from solgel-processed silica xerogels to the dissolution medium ( $\mathrm{SBF}$ - simulated body fluid). The aim of the work was to investigate, how inorganic and organic impurities in the silica lattice influence the microstructure of polymeric matrix and the release of drug.

\section{Materials and methods}

\section{Materials}

Tetramethoxysilane (TMOS, $\mathrm{C}_{4} \mathrm{H}_{12} \mathrm{O}_{4} \mathrm{Si}$ ), hydroxyl-terminated polydimethylsiloxane (PDMS, $n=200, d=0.97)$, calcium chloride $\left(\mathrm{CaCl}_{2}\right)$ and drug-Metronidazole (2-methyl-5-nitroimidazole-1-ethanol) from Sigma Chemicals Company, were used without further purification. Ethanol and ammonium hydroxide (from POCh Co., Poland) were of analytical grade purity.

Simulated body fluid as the dissolution medium for release analysis [30] was prepared by dissolving reagent grade $\mathrm{NaCl}(136.8 \mathrm{mM}), \mathrm{NaHCO}_{3}(4.2 \mathrm{mM}), \mathrm{KCl}$ (3.0 mM), $\quad \mathrm{K}_{2} \mathrm{HPO}_{4} \cdot 3 \mathrm{H}_{2} \mathrm{O} \quad(1.0 \mathrm{mM}), \quad \mathrm{MgCl}_{2} \cdot 6 \mathrm{H}_{2} \mathrm{O} \quad(1.5 \mathrm{mM}), \quad \mathrm{CaCl}_{2} \cdot 2 \mathrm{H}_{2} \mathrm{O}$ (2.5 mM), $\mathrm{Na}_{2} \mathrm{SO}_{4}(0.5 \mathrm{mM})$ (from POCh Co., Poland, analytical grade purity) in redistilled water, and the solution was buffered with tris(hydroxymethyl)aminomethane [TRIZMA] (from Sigma) and hydrochloric acid to $\mathrm{pH}$ 7.40. 
Apparatus

A Hewlett Packard 8452A UV-VIS spectrophotometer was used for spectral measurements over time in the studies of drug release and matrix degradation.

A magnetic stirrer Heidolph MR Hei-Standard equipped with Contact Thermometer EKT Hei-Con with stainless steel sensor (Germany) was used for controlling the release conditions.

A Micromeritics ASAP 2405N apparatus was used for measurements of specific surface area and pore size of the xerogels.

A Jasco FTIR-410 spectrometer was used for the analysis of the chemical composition of silica xerogels.

A Hitachi Scanning Electron Microscope (SEM) S-2500 (Tokyo, Japan) was used for examining the microstructure of xerogels.

Preparation of Metronidazole-doped silica xerogels

Silica $\left(\mathrm{SiO}_{2}\right)$, calcium silicate $\left(\mathrm{SiO}_{2}-\mathrm{CaO}\right), \mathrm{SiO}_{2}-\mathrm{PDMS}$ and $\mathrm{SiO}_{2}-\mathrm{CaO}-\mathrm{PDMS}$ hybrid inorganic-organic materials, all mixed with a model drug-Metronidazole, were prepared by means of sol-gel process [17] under ambient conditions. The mole ratio of the silica sols were TMOS:PDMS $=2: 1$, TMOS: $\mathrm{CaCl}_{2}=6: 1$, TMOS: $\mathrm{H}_{2} \mathrm{O}=1: 4, \mathrm{pH}_{\text {sol }}=9$. Gels thus obtained were dried at $50{ }^{\circ} \mathrm{C}$ for 3 days. Crackfree monoliths were obtained. The procedures of obtaining different types of xerogels are given below:

$\mathrm{SiO}_{2}$ : a solution of $2.53 \mathrm{~mL}$ TMOS precursor in $8 \mathrm{~mL} \mathrm{MeOH}, 1.2 \mathrm{~mL}$ water, $0.02 \mathrm{~mL}$ of $25 \% \mathrm{NH}_{3} \cdot \mathrm{H}_{2} \mathrm{O}$ and $0.25 \mathrm{mg}$ of Metronidazole in $2 \mathrm{~mL} \mathrm{MeOH}$ were mixed to form homogenous gel. The gelation time for this sol was $15 \mathrm{~min}$.

$\mathrm{SiO}_{2}-\mathrm{CaO}$ : a solution of $2.2 \mathrm{~mL}$ TMOS precursor in $5 \mathrm{~mL} \mathrm{MeOH}$ and a solution of $0.28 \mathrm{mg}$ of $\mathrm{CaCl}_{2}$ in $3 \mathrm{~mL} \mathrm{MeOH}$ were separately stirred for $0.5 \mathrm{~h}$. After that, the prepared solutions were mixed, and $1 \mathrm{~mL}$ water, $0.018 \mathrm{~mL}$ of $25 \% \mathrm{NH}_{3} \cdot \mathrm{H}_{2} \mathrm{O}$ and $0.25 \mathrm{mg}$ of Metronidazole in $2 \mathrm{~mL} \mathrm{MeOH}$ were added to form the homogenous gel. The gelation time for this sol was $10 \mathrm{~min}$.

$\mathrm{SiO}_{2}-\mathrm{PDMS}$ : a solution of $2.0 \mathrm{~mL}$ TMOS precursor in $4 \mathrm{~mL} \mathrm{MeOH}$ and a solution of $0.51 \mathrm{~mL}$ PDMS in $4 \mathrm{~mL} \mathrm{MeOH}$ were separately stirred for $0.5 \mathrm{~h}$. After that, the prepared solutions were mixed, and $1 \mathrm{~mL}$ water, $0.018 \mathrm{~mL}$ of $25 \%$ $\mathrm{NH}_{3} \cdot \mathrm{H}_{2} \mathrm{O}$ and $0.25 \mathrm{mg}$ of Metronidazole in $2 \mathrm{~mL} \mathrm{MeOH}$ were added to form the homogenous gel. The gelation time for this sol was $20 \mathrm{~min}$.

$\mathrm{SiO}_{2}-\mathrm{CaO}-\mathrm{PDMS}$ : a solution of $2.0 \mathrm{~mL}$ TMOS precursor in $4 \mathrm{~mL} \mathrm{MeOH}$, a solution of $0.51 \mathrm{~mL}$ PDMS in $4 \mathrm{~mL} \mathrm{MeOH}$ and a solution of $0.25 \mathrm{mg}$ of $\mathrm{CaCl}_{2}$ in $1 \mathrm{~mL} \mathrm{MeOH}$ were separately stirred for $0.5 \mathrm{~h}$. After that, the TMOS and PDMS prepared solutions were mixed for $0.5 \mathrm{~h}$, and then $\mathrm{CaCl}_{2}$ solution, $1 \mathrm{~mL}$ water and $0.016 \mathrm{~mL}$ of $25 \% \mathrm{NH}_{3} \cdot \mathrm{H}_{2} \mathrm{O}$ and $0.25 \mathrm{mg}$ of Metronidazole in $2 \mathrm{~mL} \mathrm{MeOH}$ were added to form the homogenous gel. The gelation time for this sol was $15 \mathrm{~min}$. 
Analysis

\section{Textural properties}

The bulk density of the obtained xerogels was calculated from sample weight and volume.

The porosity of the samples was quantified by surface area and average pore size measurements.

Specific surface area and pore size of the xerogels were measured using the BET technique based on nitrogen gas adsorption. Before the measurement, the samples were crushed and degassed at $200{ }^{\circ} \mathrm{C}$. The specific surface area was calculated from the BET equation. An average pore size was calculated by the $\mathrm{BJH}$ method based on the desorption branch of the isotherm.

The morphology of xerogels was observed using scanning electron microscope.

For SEM, the silica xerogel specimens were mounted on stubs and dried overnight in a vacuum desiccator. Prior to microscopy, the specimens were sputter coated with gold (Edwards, Model s150B Sputter Coater). Subsequently, the specimens were photographed, and the microstructure of the silica xerogels was examined with a scanning electron microscope.

\section{Molecular (chemical) structure}

The chemical composition of silica xerogels was determined with the FTIR spectrometer. The spectra were measured over a range of $4000-650 \mathrm{~cm}^{-1}$ with an instrument resolution of $4 \mathrm{~cm}^{-1}$. Each individual spectrum was an average of 36 scans. In this measurement, the pulverized silica xerogels were mixed homogeneously with $\mathrm{KBr}$ powder, and the background noise was corrected with pure $\mathrm{KBr}$ data.

\section{Stability study}

Stability of the matrices was evaluated by the spectrophotometric method based on the formation of silic-molybdenic blue complex $\left(\lambda_{\max }=814 \mathrm{~nm}\right)$ to determine the dissolved $\mathrm{Si}(\mathrm{OH})_{4}$ [31]. The silica xerogel samples were soaked in SBF solution $(0.5 \mathrm{~g} / 50 \mathrm{~mL})$. The intervals were selected based on the silica xerogel matrix degradation rate. The solutions were analysed daily. The SBF solution was replaced following each analysis.

The dissolved $\mathrm{Si}(\mathrm{OH})_{4}$ reacted with ammonium molybdate $(5 \%)$ in $\mathrm{pH}=1$ to form silic-molybdenic acid. Then, $0.25 \%$ Mohr's salt (hydrated ammonium iron(II) sulphate) was added to the silic-molybdenic acid solution to obtain silicmolybdenic blue complex. Subsequently, the absorbance value at the maximum absorbance of silic-molybdenic blue complex was measured at wavelength $\lambda_{\max }=814 \mathrm{~nm}$. 


\section{Drug release monitoring}

The drug release process was evaluated via diffusion of Metronidazole from the pores of the xerogel matrices.

Silica xerogel samples were soaked in $20 \mathrm{~mL}$ of SBF as the dissolution medium and were stirred at $50 \mathrm{rpm}$ at $37^{\circ} \mathrm{C}$. The kinetic process was monitored spectrophotometrically by measuring the absorbance values at the maximum absorbance of Metronidazole at a wavelength $\lambda=320 \mathrm{~nm}$ (in the UV region from 220 to $390 \pm 0.1 \mathrm{~nm}$, measured quantity absorbance $A \pm 0.005$ a.u.). The experiments were carried out in duplicate; therefore, only mean values with SD error bars are reported.

Approximation equation at the confidence interval at level $0.05(p=0.05)$ and correlation coefficient $R=0.995$ :

$$
A=0.0518 \cdot C+0.0151,
$$

with which the dependence between absorbance $(A)$ and therapeutic agent concentration $(C)$ was described, made it possible to determine the amount of released drug in the time function $t(\mathrm{~min})$.

\section{Results and discussion}

Physical properties

Figure 2 shows the nitrogen adsorption-desorption isotherms for the different samples of xerogels. According to the Brunauer, Deming, Deming and Teller (BDDT) classification, the isotherms obtained for $\mathrm{SiO}_{2}-\mathrm{CaO}$ xerogel at $200{ }^{\circ} \mathrm{C}$, is of type I (Fig. 2a), which is characteristic of a microporous material (pore radii $<2 \mathrm{~nm}$ ). A high volume is absorbed at the lowest relative pressure, which indicates a large volume of very small pores. The virtual lack of hysteresis in the desorption branch means that the pores are as large as the openings leading into them.

The isotherm for the other samples is of type IV (Fig. 2b-d). These isotherms show low adsorption at low relative pressures, and a sudden increase in adsorption occurs at high pressure, which is characteristic of a mesoporous solid (pore radii $\geq 2 \mathrm{~nm}$ ). The occurrence of hysteresis in the desorption branch is attributed to the presence of pore cavities larger in diameter than the openings leading into them $[32,33]$.

Table 1 summarizes the physical properties of xerogels derived from the isotherm analysis: BET surface area $\left(S_{\mathrm{BET}}\right)$, pore volume $\left(V_{\mathrm{mp}}\right)$, mean pore radius $\left(r_{\mathrm{mp}}\right)$ and also bulk density $(\rho)$ of the obtained xerogels.

The pure silica xerogel exhibited the high surface area and the largest average pore size. The $\mathrm{SiO}_{2}-\mathrm{CaO}$ xerogel showed a negligible increase in surface area but a decrease in pore volume and pore radius. Modification of material by adding PDMS decreased both the surface area and the average pore size that indicates decreased porosities of the samples. This effect is associated with the formation linear, weak 
(a)

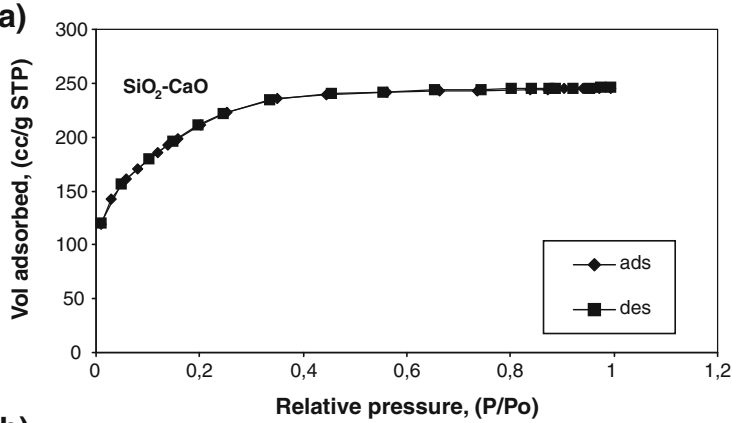

(b)

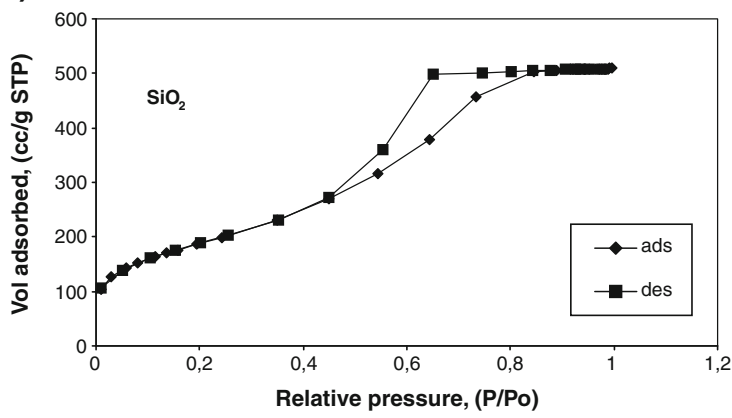

(c)
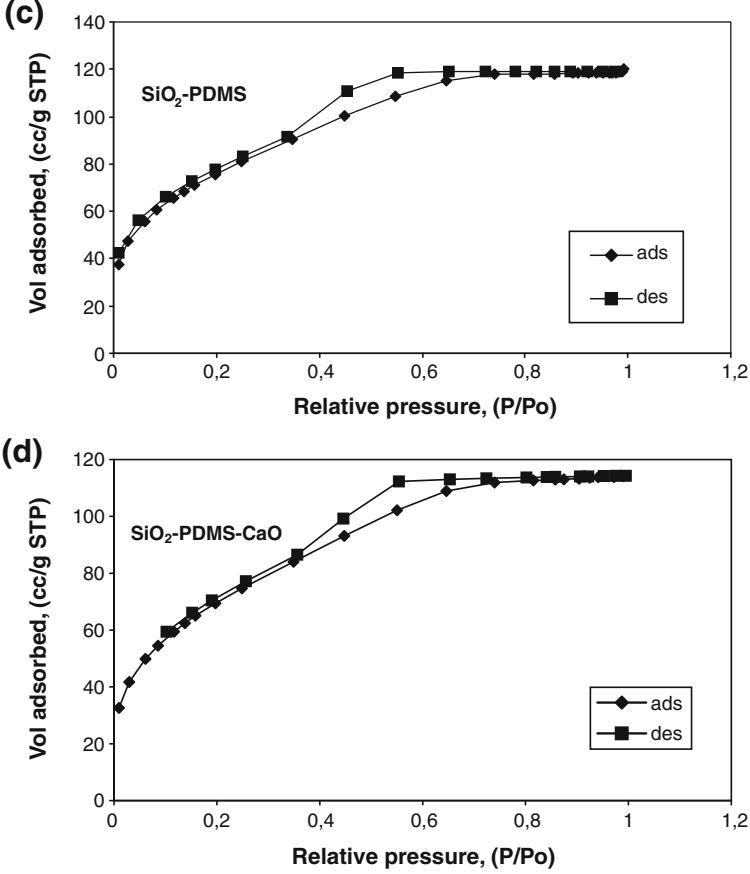

Fig. 2 Nitrogen adsorption-desorption isotherms of xerogels: $\mathbf{a} \mathrm{SiO}_{2}-\mathrm{CaO}, \mathbf{b} \mathrm{SiO}_{2}, \mathbf{c ~} \mathrm{SiO}_{2}-\mathrm{PDMS}$ and d $\mathrm{SiO}_{2}-\mathrm{PDMS}-\mathrm{CaO}$ 
Table 1 Some physical properties of the obtained xerogels: pore size $\left(r_{\mathrm{mp}}\right)$, surface area $\left(S_{\mathrm{BET}}\right)$, pore volume $\left(V_{\mathrm{mp}}\right)$ and bulk density $(\rho)$

\begin{tabular}{lllll}
\hline Sample & $r_{\text {mp }}(\AA)$ & $S_{\text {BET }}\left(\mathrm{m}^{2} \mathrm{~g}^{-1}\right)$ & $V_{\mathrm{mp}}\left(\mathrm{cm}^{3} \mathrm{~g}^{-1}\right)$ & $\rho\left(\mathrm{g} \mathrm{cm}^{-3}\right)$ \\
\hline $\mathrm{SiO}_{2}$ & 46.9456 & 670 & 0.83 & 1.06 \\
$\mathrm{SiO}_{2}-\mathrm{CaO}$ & 20.1914 & 752 & 0.253 & 1.83 \\
$\mathrm{SiO}_{2}-\mathrm{PDMS}$ & 26.8677 & 273 & 0.18 & 1.41 \\
$\mathrm{SiO}_{2}-\mathrm{PDMS}-\mathrm{CaO}$ & 27.9589 & 252 & 0.21 & 1.42 \\
\hline
\end{tabular}

crosslinking polymers because of the group $-\mathrm{CH}_{3}$ from PDMS which does not undergo hydrolysis.

The more porous structure of samples correlated well with a decrease of densities of samples from $1.83 \mathrm{~g} / \mathrm{cm}^{3}$ for Ca-modified silica (characteristic for a polymer with very small pores) to $1.06 \mathrm{~g} / \mathrm{cm}^{3}$ for non-modified silica on the largest average pore size.

Figure 3 shows the scanning electron images of the silica xerogel (Fig. 3a) and $\mathrm{SiO}_{2}$-PDMS xerogel (Fig. 3b). It is clearly observed that morphology of samples changes from globular structure for non-modified silica to sample with dense morphology for that prepared using PDMS as additive. Xerogels without addition of PDMS have a structure with several smaller agglomerates joining together to form a larger cluster, while the xerogels with PDMS have a unbranched and less convoluted structure. Xerogels with addition of $\mathrm{CaO}$, due to the low content of the calcium oxide, have very similar morphology to their counterparts without calcium oxide $\left(\mathrm{SiO}_{2}\right.$ and $\mathrm{SiO}_{2}-\mathrm{CaO} ; \mathrm{SiO}_{2}-\mathrm{PDMS}$ and $\left.\mathrm{SiO}_{2}-\mathrm{PDMS}-\mathrm{CaO}\right)$.
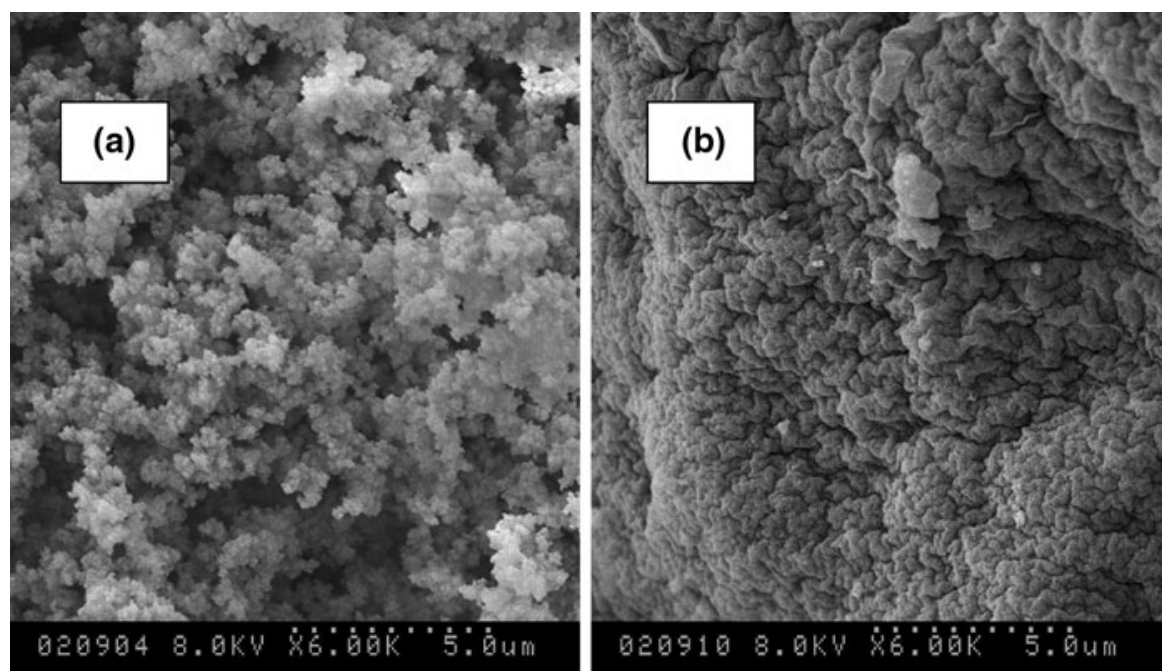

Fig. 3 SEM micrographs for $\mathbf{a} \mathrm{SiO}_{2}$ and $\mathbf{b} \mathrm{SiO}_{2}-\mathrm{PDMS}$ xerogels. The 10-division scale equals $5.0 \mu \mathrm{m}$ 
The FTIR spectra of silica xerogels are shown in Fig. 4. The general features of the spectra of all the silica xerogels are not significantly different. All spectra present the peaks at:

$3500-3750 \mathrm{~cm}^{-1}$-associated with $\mathrm{H}$-bonded $\mathrm{SiOH}$ stretching vibrations and

H-bonded water;

$1650 \mathrm{~cm}^{-1}$ — corresponds to vibrations of water molecule;

$1075 \mathrm{~cm}^{-1}$ — corresponds to asymmetric stretching vibrations of $\mathrm{Si}-\mathrm{O}-\mathrm{Si}$ bridging sequences;

$795 \mathrm{~cm}^{-1}$ — corresponds to symmetric stretching vibrations of $\mathrm{Si}-\mathrm{O}-\mathrm{Si}$ bonds belonging to ring structures.

Additional peaks at 2800, 1260 and $795 \mathrm{~cm}^{-1}$ are observed when PDMS was used for the sample preparation. The band at $2800 \mathrm{~cm}^{-1}$ is assigned to the fundamental stretching vibrations of $\mathrm{C}-\mathrm{H}$ bonds. The bands at 1260 and $795 \mathrm{~cm}^{-1}$ are due to the bending vibrations of $\mathrm{Si}-\mathrm{CH}_{3}$ bonds belonging to PDMS [34, 35].

Significant differences exist for the intensity of the band in the range 4000$2000 \mathrm{~cm}^{-1}$ for the samples with PDMS and without PDMS. The intensity of the bond responsible for oscillations in the $\mathrm{O}-\mathrm{H}$ group is lower for the silica xerogels that were modified PDMS. This is because of the hydrophobic nature of PDMS that reduces the $\mathrm{O}-\mathrm{H}$ group and the water molecules inside of xerogel lattices.

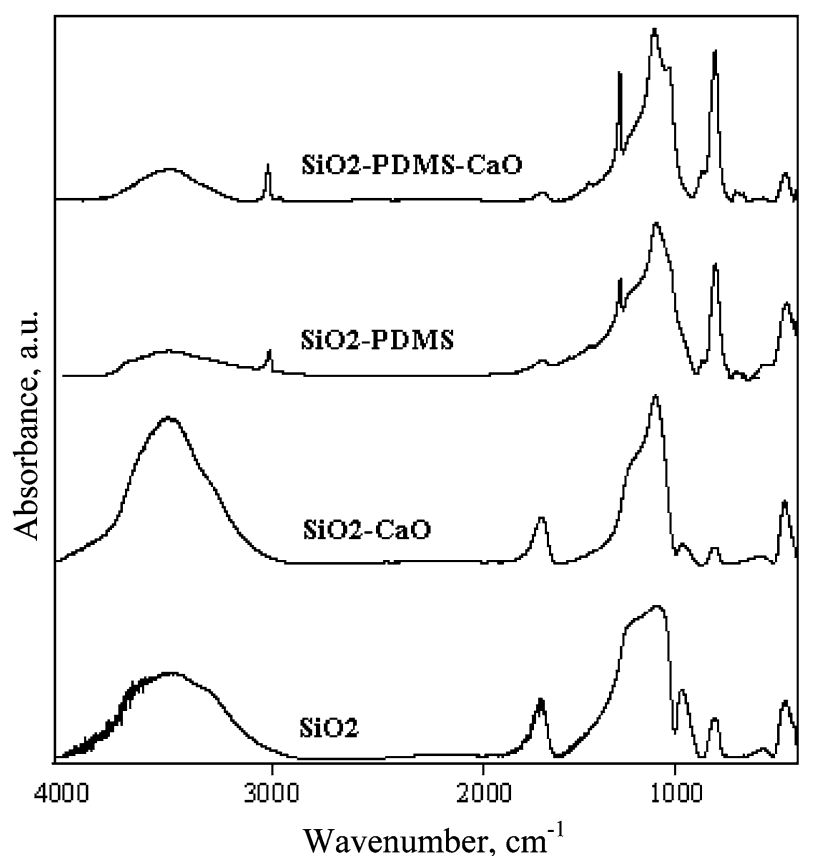

Fig. 4 FTIR spectra of four representative xerogel samples: $\mathrm{SiO}_{2}, \mathrm{SiO}_{2}-\mathrm{CaO}, \mathrm{SiO}_{2}-\mathrm{PDMS}$ and $\mathrm{SiO}_{2}-$ PDMS-CaO 
Spectral differences for the samples with $\mathrm{CaO}$ and without $\mathrm{CaO}$ are negligible. Bands belonging to $\mathrm{CaO}$, occurring in the region of $1700-1460 \mathrm{~cm}^{-1}$, are masked or occur together with strong bands assigned to the vibration of water molecules.

Study of the stability of the xerogel matrices

Application of variable precursors during silica xerogel synthesis affected the degradation of the silica xerogel matrix in vitro (Fig. 5).

The tests of the matrix degradation showed, that generally, the degradation proceeds very slowly $(0.52-1.2 \%$ per 70 days) in a linear manner.

$\mathrm{SiO}_{2}$ matrix degrades in greatest degree. $\mathrm{SiO}_{2}$ xerogels are hydrophilic polymer with silanol polar groups on the surface which attract the polar water molecules, so this matrix takes up large quantities of water and degrades by hydrolysis of the siloxane bonds through the entire network [36].

Partial substitution of $\mathrm{SiO}_{2}$ with $\mathrm{CaO}$ and especially with PDMS results in decreasing of degree of matrix degradation. This effect could be due to the increasing hydrophobic character of the matrix (effect of PDMS) and the diminishing of porosity (effect of $\mathrm{CaO}$ ). These two factors make it difficult for a surrounding fluid to penetrate and dissolve the modified silica xerogel matrices. The study of matrix stability indicates that the low degradation of xerogels also has little effect on the drug release.

Testing the release of Metronidazole from silica xerogels

Figure 6 displays the plot of the data expressed as the cumulative amount of Metronidazole released from the xerogel matrices as a function of time. The findings show that modification of silica xerogel by adding $\mathrm{CaO}$ and PDMS resulted in a decrease in cumulative percent drug release.

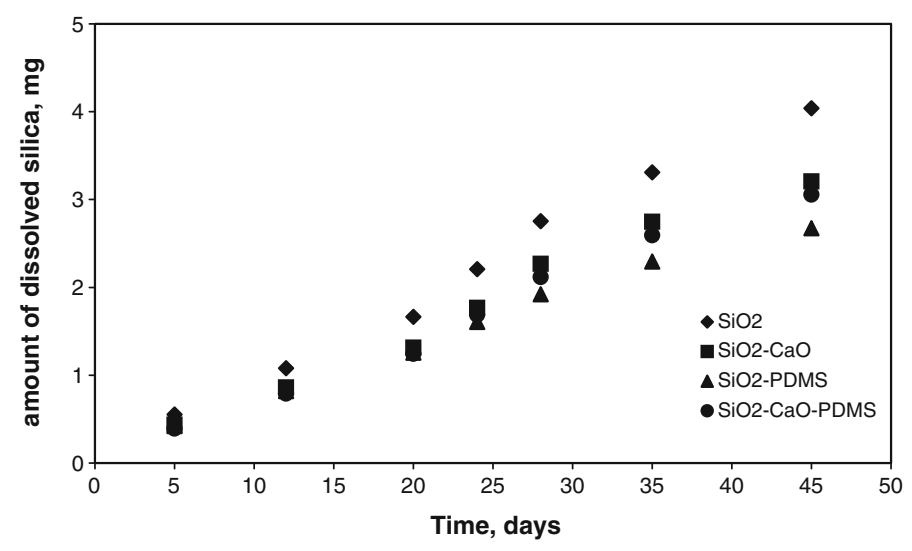

Fig. 5 Degradation of xerogel matrices 


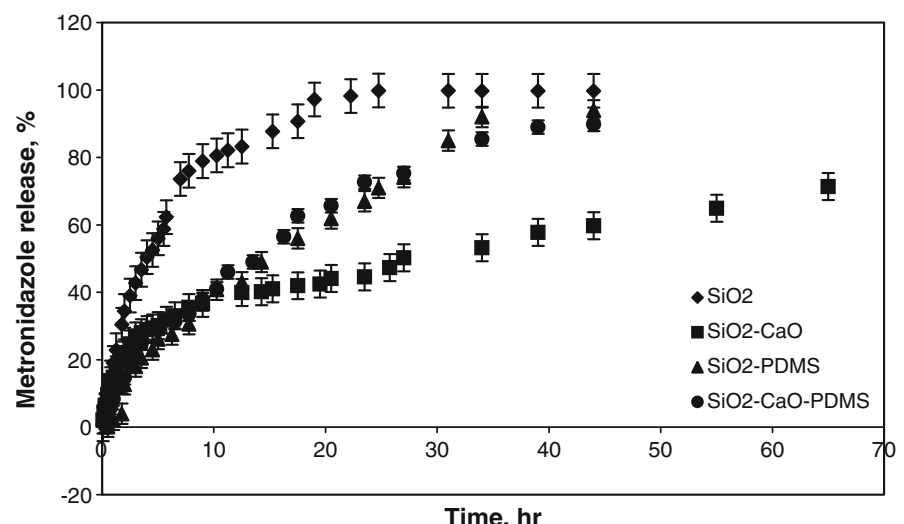

Fig. 6 Release of Metronidazole from xerogel matrices

The formulations displayed negligible different release profiles. The Metronidazole was released from $\mathrm{SiO}_{2}$ and $\mathrm{SiO}_{2}-\mathrm{CaO}$ matrices in a biphasic way characterized by a faster initial release followed by a slower, steady release.

The silica xerogels modified the PDMS release of drug more monotonously.

In the case of $\mathrm{SiO}_{2}$ matrix, Metronidazole is released rapidly in the first $4 \mathrm{~h}$ $(50 \pm 2.1 \%)$, and then gradually reaches a residual value $(98 \pm 1.8 \%)$ over the next $20 \mathrm{~h}$.

In case of $\mathrm{SiO}_{2}-\mathrm{CaO}$ matrix, the rate of the drug release took place faster up to about $2 \mathrm{~h}(25 \pm 2.5 \%)$, then the process has become slower. Overall, after $60 \mathrm{~h}$ of the experiment, the maximum amount of Metronidazole released was $71 \pm 4 \%$.

Xerogels, $\mathrm{SiO}_{2}-\mathrm{PDMS}$ and $\mathrm{SiO}_{2}-\mathrm{PDMS}-\mathrm{CaO}$, showed a final release of $94 \pm$ $3.2 \%$ and $90 \pm 4.3 \%$, respectively, of encapsulated Metronidazole after $44 \mathrm{~h}$ of the experiment.

Generally, the release of drug from polymeric matrices results from the combination of diffusion, erosion and swelling of the matrix.

In this study, the erosion of the xerogels is very slowly (0.52-1.2\% per 70 days), while drug release proceed within 1-3 days. Thus, it is reasonable to assume that the low degradation of xerogels has little effect on the drug release.

Matrix swelling occurs in organic hydrogels with the carbon scaffold. In hybrid silica xerogels used for the purpose of this study, there are organic groups constituting end $-\mathrm{CH}_{3}$ group in silica scaffold. Thus, in the case of $\mathrm{SiO}_{2}-\mathrm{PDMS}$ xerogels, matrix swelling is not important factor in drug release.

The release of Metronidazole mainly involves the process of diffusion, controlled from the pores of the xerogels.

In order to confirm the diffusional mechanisms of drug release, release data were fitted using a semi-empirical Higuchi equation:

$$
M_{t} / M_{\infty}=k t^{1 / 2}
$$

where the constant $k$ depends upon the diffusion constant, the porosity and tortuosity of the matrix, the solubility of the drug in the solvent used and the initial drug 
content within the matrix and $M_{t} / M_{\infty}$ is the released quantity of the drug and $t$ represents the exposure time and $n=0.5$ is the release exponent indicating the Fickian diffusion for non-swelling polymers [37, 38].

Figure 7 shows the correlation between $M_{t} / M_{\infty}$ and $t^{1 / 2}$ in all Metronidazolesilica composites, following Eq. 2. Rectilinear dependence between the amount of the released substance $(\%)$ and the square root of the release time $(t)$ suggests that the Metronidazole is released from the PDMS-modified xerogel samples by diffusion. In the case of $\mathrm{SiO}_{2}$ and especially $\mathrm{SiO}_{2}-\mathrm{CaO}$ xerogels with Metronidazole, was observed the lack of rectilinearity of the final part of the discussed dependence. This effect could be due to the complete dissolving of more easily available drug molecules in the superficial layers of xerogels and slowed release of model drug from the inner part of matrix.

The drug delivery profiles are dependent on chemical composition and physical properties of xerogels.

In the case of silica xerogel, the higher release rate of the drug may be attributed to its increased hydrophilicity. The hydrophilic matrix facilitates SBF solution penetration inside the silica lattice, dissolves the incorporated molecules of drug and accelerates the drug molecules diffusion from the matrix to the surrounding fluid.

The observed decrease of Metronidazole release from PDMS-modified xerogels may be due to steric reasons (both the hydrophobic nature of the $\mathrm{CH}_{3}$-groups from PDMS inside the pores and small porosity of xerogel lattice), making it difficult for drug molecules to pass to the water phase.

In the case of $\mathrm{CaO}$-modified xerogels, the lower release rate of the drug may be attributed to its decreased pore size. During the first $2 \mathrm{~h}$ of release, the release proceeds mainly by dissolution and diffusion of drug in the superficial layers of xerogel and, additionally, by diffusion of $\mathrm{Ca}^{2+}$ ions in contact with water solution. Therefore, Metronidazole was released quickly at first, in spite of small porosity. Within the inner part of xerogel, microporous network of matrix effectively immobilized Metronidazole molecules, making it difficult for the drug to pass to the surrounding fluid.

\section{Conclusions}

The sol-gel method is a powerful approach for producing inorganic and hybrid, inorganic-organic materials with different morphology and physical properties, which may be applied in the medicine and the pharmaceutical industry. These features can be readily modulated by partially replacing TMOS with organic or inorganic components.

In this study, carrier matrices used the $\mathrm{SiO}_{2}, \mathrm{SiO}_{2}-\mathrm{CaO}, \mathrm{SiO}_{2}-\mathrm{PDMS}$ and $\mathrm{SiO}_{2}-$ CaO-PDMS xerogels. The modifications of silica xerogel may improve its properties: the bioactivity (due to the addition of calcium ions) and flexibility (due to the use of PDMS). Consequently, these matrices may be useful as the bonesubstitute materials.

The pure silica xerogel exhibited the high surface area and the largest average pore size. The $\mathrm{SiO}_{2}-\mathrm{CaO}$ xerogel showed a negligible increase in surface area but a 
Fig. 7 Kinetics of

Metronidazole release from xerogels: a $\mathrm{SiO}_{2}, \mathbf{b} \mathrm{SiO}_{2}-\mathrm{CaO}$,

c $\mathrm{SiO}_{2}-\mathrm{PDMS}$ and

d $\mathrm{SiO}_{2}-\mathrm{PDMS}-\mathrm{CaO}$

to surrounding solution (a)

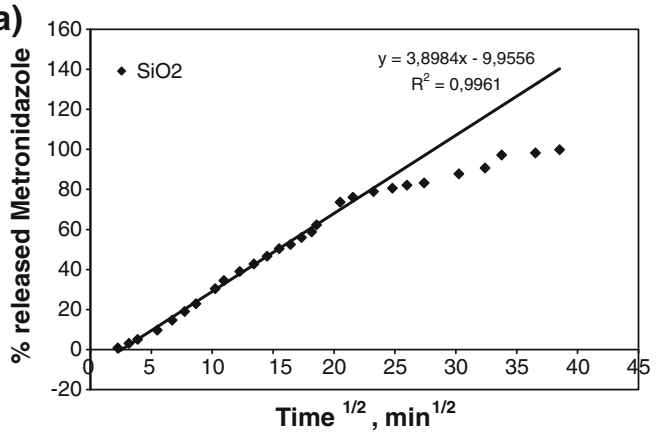

(b)
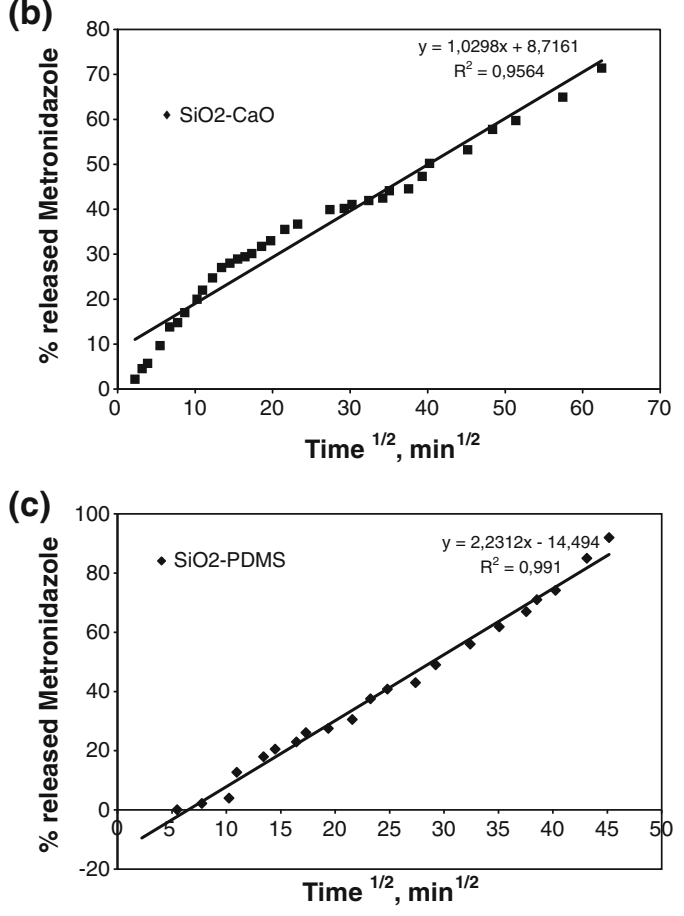

(d)

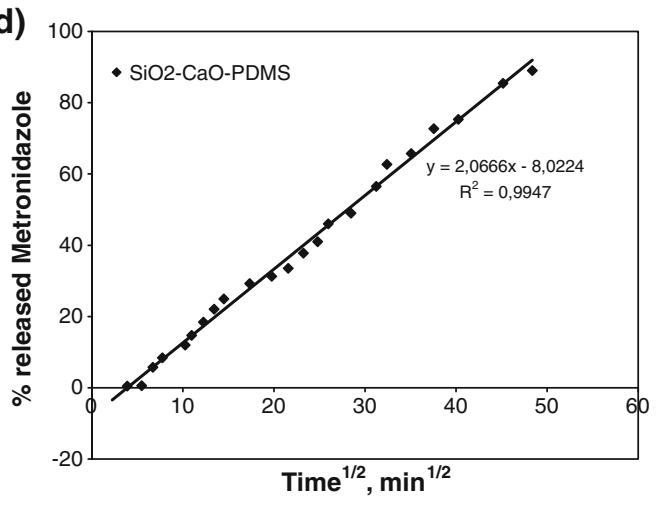


decrease in pore volume and pore radius. Modification of material by adding PDMS decreased both the surface area and the average pore size. Moreover, partial substitution of $\mathrm{SiO}_{2}$ with $\mathrm{CaO}$ and especially with PDMS results in decreasing of degree of matrix degradation.

The sol-gel method used to synthesize xerogels containing Metronidazole was also found to be useful for the synthesis of controlled release drug delivery systems.

The xerogel/Metronidazole material showed a similar diphasic release profile of the drug, whose mechanism was found to be diffusion controlled.

The percent of cumulative release of Metronidazole from silica xerogels was strongly correlated with physical properties of matrices. From the four types of xerogels tested, pure silica matrix of greatest hydrophilicity and biggest pore size was much more effective than modified silica xerogels. Xerogels, $\mathrm{SiO}_{2}, \mathrm{SiO}_{2}-$ PDMS and $\mathrm{SiO}_{2}-\mathrm{PDMS}-\mathrm{CaO}$, showed a final Metronidazole release of $\sim 100,94$ and $\sim 90 \%$, respectively, while $\mathrm{SiO}_{2}-\mathrm{CaO}$ xerogel showed a final release of $71 \%$ of encapsulated Metronidazole.

The reports [10, 39, 40], which exhibit biocompatibility and bioactivity sol-gel ceramics combined with this study, suggest that these xerogel materials could be promising candidates for formulation in local delivery systems as controlled release materials for the treatment of bone infections or for repairing periodontal defects in dentistry.

Open Access This article is distributed under the terms of the Creative Commons Attribution Noncommercial License which permits any noncommercial use, distribution, and reproduction in any medium, provided the original author(s) and source are credited.

\section{References}

1. Dave BC, Dunn B, Selverstone J, Valentine D, Zink JI (1994) Sol-gel encapsulation methods for biosensors. Anal Chem 66:1120A-1127A

2. Blyth DJ, Poynter SJ, Russel DA (1996) Calcium biosensing with a sol-gel immobilized photoprotein. Analyst 121:1975-1978

3. Li C-J, Lin Y-H, Shih C-L, Tsaur J-P, Chan L-K (2002) Sol-gel encapsulation of lactate dehydrogenase for optical sensing of L-lactate. Biosens Bioelectron 17:323-330

4. Wu S, Lin J, Chan SI (1994) Oxidation of dibenzothiophene catalyzed by heme-containing enzymes encapsulated in sol-gel glass. A new form of biocatalysts. Appl Biochem Biotechnol 47:11-17

5. Ahola M, Kortesuo P, Kangasniemi I, Kiesvaara J, Yli-Urpo AU (2000) Silica xerogel carrier material for controlled release of toremifene citrate. Int J Pharm 195:219-227

6. Czarnobaj K, Czarnobaj J (2008) Sol-gel processed porous silica carriers for the controlled release of diclofenac diethylamine. J Biomed Mater Res B 87B:114-120

7. Nguyen DT, Smit M, Dunn B, Zink JI (2002) Stabilization of creatine kinase encapsulated in silicate sol-gel materials and unusual temperature effects on its activity. Chem Mater 14:4300-4306

8. Sieminska L, Zerda TW (1996) Diffusion of steroids from sol-gel glass. J Phys Chem 100:45914597

9. de Gaetano F, Ambrosio L, Raucci MG, Marotta A, Catauro M (2005) Sol-gel processing of drug delivery materials and release kinetics. J Mater Sci Mater Med 16:261-265

10. Radin S, Falaize S, Lee MH, Ducheyne P (2002) In vitro bioactivity and degradation behavior of silica xerogels intended as controlled release materials. Biomaterials 23:3113-3122

11. Kortesuo P, Ahola M, Kangas M, Lein T, Laakso S, Vuorilehto L, Yli-Urpo A, Kiesvaara J, Marvola M (2001) In vitro release of dexmedetomidine from silica xerogel monoliths: effect of sol-gel synthesis parameters. Int J Pharm 221:107-114 
12. Tsuru K, Aburatani Y, Yabuta T, Hayakawa S, Ohtsuki C, Osaka A (2001) Synthesis and in vitro behaviour of organically modified silicate containing Ca ions. J Sol-Gel Sci Technol 21:89-96

13. Domingues Z, Cortes M, Gomes T, Diniz H, Gomes J, Faria A, Sinisterra R (2004) Bioactive glass as a drug delivery system of tetracycline and tetracycline associated with $\beta$-cyclodextrin. Biomaterials 25:327-333

14. Tsuru K, Hayakawa S, Osaka A (2004) Synthesis of bioactive and porous organic-inorganic hybrids for biomedical applications. J Sol-Gel Sci Technol 32:201-205

15. Schmidt H (1988) Chemistry of material preparation by the sol-gel process. J Non-Cryst Solids 100:51-64

16. Buckley AM, Greenblatt M (1994) The sol-gel preparation of silica gels. J Chem Educ 71:599-602

17. Livage J, Sanchez C (1994) Sol-gel chemistry. J Non-Cryst Solids 45:11-19

18. Osada Y, Gong JP, Tanaka Y (2004) Polymer gels. J Macromol Sci C C44:87-112

19. Chen KC, Tsuchiya T, Mackenzie JD (1986) Sol-gel processing of silica. I. The role of the starting compounds. J Non-Cryst Solids 81:227-237

20. Ro JC, Chung IJ (1991) Structures and properties of silica gels prepared by sol-gel method. J NonCryst Solids 130:8-17

21. Curran MD, Stiegman AE (1999) Morphology and pore structure of silica xerogels made at low pH. J Non-Cryst Solids 249:62-68

22. Klein LC (1993) Sol-gel optical materials. Annu Rev Mater Sci 23:437-452

23. Jones D, Woolfson A, Brown A, O’Neill M (1997) Mucoadhesive, syringeable drug delivery systems for controlled application of metronidazole to the periodontal pocket: in vitro release kinetics, syringeability, mechanical and mucoadhesive properties. J Control Release 49:71-79

24. Kostowski W, Herman Z (2005) Farmakologia. Wyd. Lekarskie PZWL, Warszawa

25. Perioli L, Ambrogi V, Rubini D, Giovagnoli S, Ricci M, Blasi P, Rossi C (2004) Novel mucoadhesive buccal formulation containing metronidazole for the treatment of periodontal disease. J Control Release 95:521-533

26. Lahiani-Skiba M, Bounoure F, Shawky-Tous S, Arnaud P, Skiba M (2006) Optimization of entrapment of metronidazole in amphiphilic $\beta$-cyclodextrin nanospheres. J Pharm Biomed Anal 41:1017-1021

27. Akashi A, Matsuya Y, Unemori M, Akamine A (2001) Release profile of antimicrobial agents from $\beta$-tricalcium phosphate cement. Biomaterials 22:2713-2717

28. Quaglia F, Vignola MC, De Rosa G, La Rotonda MI, Maglio G, Palumbo R (2002) New segmented copolymers containing poly( $\varepsilon$-caprolactone) and etheramide segments for the controlled release of bioactive compounds. J Control Release 83:263-271

29. Lam A, Rivera A (2006) Theoretical study of the interaction of surfactants and drugs with natural zeolite. Microporous Mesoporous Mater 91:181-186

30. Kokubo T, Kushitani H, Sakka S, Kitsugi T, Yamamuro T (1990) Solutions able to reproduce in vivo surface-structure changes in bioactive glass-ceramic A-W. J Biomed Mater Res 24:721-731

31. Koch OG, Koch-Dedic GA (1974) Silconmolybdanblau-Verfahren. In: Koch OG, Koch-Dedic GA (eds) Handbuch der Spurenanalyse. Springer, Berlin, p 1105

32. Fidalgo A, Ilharco L (2004) Correlation between physical properties and structure of silica xerogels. J Non-Cryst Solids 347:128-137

33. Bryans T, Brawner V, Quitevis E (2000) Microstructure and porosity of silica xerogel monoliths prepared by the fast sol-gel method. J Sol-Gel Sci Technol 17:211-217

34. Łączka M, Cholewa-Kowalska K, Kogut M (2001) Organic-inorganic hybrid glasses of selective optical transmission. J Non-Cryst Solids 287:10-14

35. Łączka M, Cholewa-Kowalska K, Kulgawczyk K, Klisch M, Mozgawa W (1999) Structural examinations of gel-derived materials of the $\mathrm{CaO}-\mathrm{P}_{2} \mathrm{O}_{5}-\mathrm{SiO}_{2}$ system. J Mol Struct 511-512:223-231

36. Göpferich A (1996) Mechanisms of polymer degradation and erosion. Biomaterials 2:103-114

37. Böttcher H, Slowik P, Süb W (1998) Sol-gel carrier systems for controlled drug delivery. J Sol-Gel Sci Technol 13:277-285

38. Costa P, Sousa Lobo JM (2001) Modeling and comparison of dissolution profiles. Eur J Pharm Sci $13: 123-133$

39. Kortesuo P, Ahola M, Karlsson S, Kangasniemi I, Yli-Urpo A, Kiesvaara J (2000) Silica xerogel as an implantable carrier for controlled drug delivery-evaluation of drug distribution and tissue effects after implantation. Biomaterials 21:193-198

40. Tsuru K, Ohtsuki C, Osaka A, Iwamoto A, Mackenzie J (1997) Bioactivity of sol-gel derived organically modified silicates. J Mater Sci Mater Med 8:157-161 